Check for updates

Cite this: RSC Adv., 2018, 8, 18690

\title{
Ultraflexible, stretchable and fast-switching electrochromic devices with enhanced cycling stability $\dagger$
}

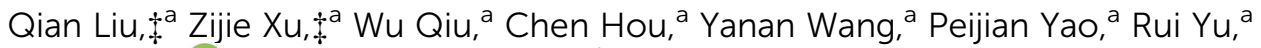 \\ Wenxi Guo (D) *a and Xiang Yang Liu*ab
}

\begin{abstract}
Ultraflexible electronics have received extensive attention due to their favorable properties, such as superior mechanical robustness, light weight and good compatibility with large-area roll-to-roll fabrication. Here we present a flexible sandwiched tungsten trioxide/silver nanotrough network/poly(3,4ethylenedioxythiophene)-poly(styrene sulfonate) multi-layer transparent conducting electrode with prominent conductivity (sheet resistance as low as $1.08 \Omega \mathrm{sq}^{-1}$ ) and transparency (85\%). In particular, the flexible transparent electrode exhibits excellent mechanical robustness upon bending and stretching. This hybrid electrode can be further adhered tightly to a layer of $\mathrm{WO}_{3}$ to form an electrochromic device, which simultaneously displays a rapid switching time $0.75 \mathrm{~s} / 1.82 \mathrm{~s}$ for bleaching/coloring) and high cyclic performance ( $86 \%$ retention of the initial optical contrast after cycling for $30000 \mathrm{~s}$ ). In addition, our electrode can also be fabricated on various flexible substrates, such as polyethylene cling wrap, polydimethylsiloxane and Ecoflex, with sustained electrochromic properties after bending, twisting, stretching and even strong kneading. Our work provides new opportunities for the next generation of flexible and wearable electronics applied on various flexible substrates.
\end{abstract}

Received 2nd April 2018

Accepted 6th May 2018

DOI: 10.1039/c8ra02829j

rsc.li/rsc-advances
Conventionally, indium tin oxide (ITO) films have been widely adopted as a transparent conducting electrode (TCE) due to their good optoelectronic properties. ${ }^{\mathbf{1 0 - 1 2}}$ However, their brittleness, low infrared transmittance and low abundance have greatly restrained their potential. ${ }^{13}$ Recent studies have reported that several other flexible devices such as conducting polymers, ${ }^{14}$ metal networks, ${ }^{15}$ and carbon materials ${ }^{16}$ are, to some extent, better alternatives to ITO. The soft molecular chains inside conducting polymers give rise to much better flexibility than traditional inorganic rigid EC materials (such as tungsten trioxide $\left(\mathrm{WO}_{3}\right)$, titanium dioxide $\left(\mathrm{TiO}_{2}\right),{ }^{17,18}$ nickel oxide (NiO) and molybdenum trioxide $\left.\left(\mathrm{MoO}_{3}\right)\right){ }^{19-21}$ carbon materials, especially carbon nanotubes and graphene, are not only abundant but also chemically stable; as for metallic networks, they have attracted great interest due to their extraordinary conductivity, achievable transparency through percolating slits in the nanowires (NWs)/grids and good compatibility with large-area rollto-roll fabrication. Despite all of these aforementioned properties, these materials still suffer from specific disadvantages. Generally, conducting polymers display a low coloring efficiency and a poor cyclic and chemical stability. The optoelectronic performance of carbon materials is relatively bad (the sheet resistance is always above $20 \Omega \mathrm{sq}^{-1}$ and transmittance is below $90 \%$ ) and better performing carbon materials are normally fabricated through thermal and plasma chemical vapor deposition methods, both of which are not economically beneficial. ${ }^{22}$ Metallic networks are always too vulnerable to corrosive 
electrolytes, especially the most widely applied silver (Ag) and copper $(\mathrm{Cu})$ networks. ${ }^{4,23}$ An ideal coating material for protecting the metallic networks requires stability in EC electrolytes while barely decreasing the optical and electrical performance of the EC electrode. Poly(3,4-ethylenedioxythiophene)-poly (styrene sulfonate) (PEDOT:PSS) is most commonly utilized due to its good conductivity, high light transparency, compatibility with solution deposition and stability in EC electrolytes. ${ }^{24-28}$

It has been reported that Lee's group ${ }^{6}$ has successfully prepared a stretchable and wearable elastic conductor by embedding a $\mathrm{WO}_{3}$ ECD and $\mathrm{Ag}$ nanowire into polydimethylsiloxane (PDMS). This unique sandwiched structure improved the mechanical robustness and durability. Cai et al. ${ }^{3}$ also developed a stable transparent electrode based on Ag grid/ PEDOT:PSS. With the protection of the PEDOT:PSS passivation layer, the atmospheric corrosion resistance and cycling stability in EC and supercapacitor applications can be enhanced. So far, most of the studies on flexible ECDs have focused on enhancing the mechanical robustness of TCEs, ${ }^{29,30}$ and there has been a lack of research on the flexibility of whole EC electrodes composed of TCE and EC films. In this regard, an ideal flexible ECD comprising both TCE and EC materials should simultaneously maintain the following properties: high flexibility, excellent chemical stability and good EC performance.

In this article, two strategies are developed to enhance the mechanical flexibility and chemical stability of a flexible transparent conducting electrode. First, a conductive film with electro-spun silver nanotrough networks (NNs) is utilized to replace ITO or Ag NWs. The Ag NNs can significantly increase the electrode's transmittance while maintaining a relatively low $R_{\mathrm{S}}{ }^{15}$ The characteristic $R_{\mathrm{S}}$ of the $\mathrm{Ag} \mathrm{NN}$ based hybrid electrode is measured to be as low as $1.08 \Omega \mathrm{sq}^{-1}$ with a transmittance of over $85 \%$. Besides, both the conductivity and the optical transparency of this electrode can be manipulated simply by controlling the density of the Ag NNs. In addition, due to the unique hollow cross-junctional structure of the Ag NNs, outstanding mechanical stability of the electrode upon bending (1.77 $\Omega \mathrm{sq}^{-1}$ increase after 5000 bending cycles) and stretching ( $7.04 \Omega \mathrm{sq}^{-1}$ increase after $100 \%$ tensile strain) can be reached. Second, to protect the $\mathrm{Ag}$ NNs from suffering from oxidation and damage during the coloring and bleaching processes, ultrathin layers of $\mathrm{WO}_{3}$ and PEDOT:PSS are adhered to the bottom and top layers of the $\mathrm{Ag}$ NNs, respectively. When this complex electrode is further compounded with a layer of $\mathrm{WO}_{3}$ to form an EC film, up to $95 \%$ excellent transparency can be realized. Moreover, a rapid switching time $(0.75 \mathrm{~s} / 1.82 \mathrm{~s}$ for bleaching/ coloring) and a high cyclic performance ( $86 \%$ retention of the initial optical contrast after cycling for $30000 \mathrm{~s}$ ) can also be simultaneously obtained. To further test the hybrid EC film's flexibility and mechanical stability, we successfully designed and fabricated extremely soft ECDs based on transparent polyethylene (PE) cling wrap, polydimethylsiloxane (PDMS) and Ecoflex substrates. It is shown that all of these ECDs can sustain their EC properties after bending, twisting, stretching and even strong kneading. In this regard, our EC films should also be extended to fabricate the next generation of flexible and wearable electronics applied on various flexible substrates. Simply by sticking these EC films onto the glass of cars and buildings, energy conservation should be realized. Furthermore, a considerable application prospect in energy storage, such as supercapacitors with extraordinary charging/discharging stabilities that can sense changes by color mutation, is proved after cycling for $50000 \mathrm{~s}$.

\section{Experimental}

\section{Preparation of the hybrid EC electrodes}

Fabrication of $\mathrm{WO}_{3} / \mathrm{Ag}$ NN/PEDOT:PSS electrodes. All reagents used were of analytical grade and used without additional purification. The Ag NNs were fabricated using electrostatic-spinning and sputtering methods as reported previously: free-standing polyvinyl alcohol (PVA) (15 wt\% in water) nanofibers were spun on an aluminum frame to form a network as the mask using an electrospinning machine (Ion Beam Technology WL-2), and then a thin layer of magnetron sputtered silver with a thickness of 50-100 nm was deposited using automatic magnetron sputtering apparatus (Jinshengweina MSP-620). The Ag NNs were transferred to a film with the pre-sputtered ultra-thin $\mathrm{WO}_{3}(10-30 \mathrm{~nm})$ on a polyethylene glycol terephthalate (PET) substrate. Firstly, deionized water was sprayed on the surface of the PET/ $/ \mathrm{WO}_{3}$ substrate. Then, the hybrid EC substrate was placed in the groove of the aluminum frame with Ag NN/PVA and vertically lifted until all of the Ag NNs were attached to the substrate. It was then soaked in deionized water for $1 \mathrm{~h}$ to remove the PVA networks. The percolated PEDOT:PSS $\left(1.45 \%\right.$ dispersion in $\mathrm{H}_{2} \mathrm{O}$, purchased from Clevios $\mathrm{PH} 1000$ ) as a protective layer was spin-coated on the PET/ $\mathrm{WO}_{3} / \mathrm{Ag}$ NN film twice at $800 \mathrm{rpm}$ for $8 \mathrm{~s}$ and then at $2000 \mathrm{rpm}$ for $30 \mathrm{~s}$, and then annealed at $90^{\circ} \mathrm{C}$ for $30 \mathrm{~min}$ to cure the PEDOT:PSS to obtain the hybrid $\mathrm{WO}_{3} / \mathrm{Ag}$ NN/PEDOT:PSS electrode film.

The fabrication procedures for the stacked hybrid EC film are schematically represented in Fig. 1 . As can be seen from

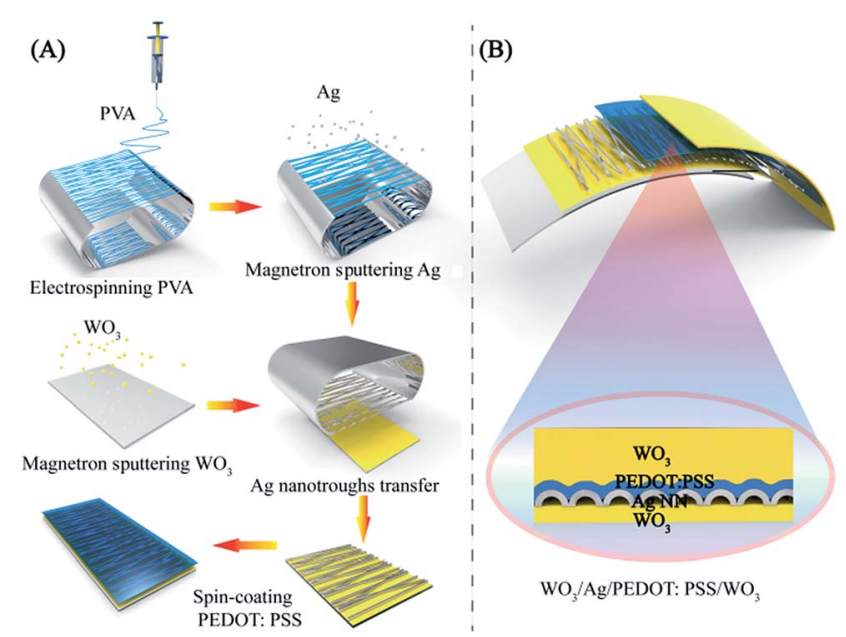

Fig. 1 (A) Fabrication procedure of the $\mathrm{WO}_{3} / \mathrm{Ag}$ NN/PEDOT:PSS transparent electrodes. (B) Schematic illustration of a cross-section of the $\mathrm{WO}_{3} / \mathrm{Ag}$ NN/PEDOT:PSS/WO 3 hybrid EC film. 
Fig. 1A, firstly, free-standing PVA nanofibers were spun on an aluminum frame through electrospinning. Secondly, the network PVA fibers as templates were coated with a thin layer of $\mathrm{Ag}$ film by magnetron sputtering. In this way, the network templates could be utilized to deposit various metal films and retain bulk-like electrical conductivity. Thirdly, the asfabricated $\mathrm{Ag}$ NN/PVA networks were transferred onto a $\mathrm{WO}_{3} /$ PET substrate and the hollow structural Ag NNs were derived after removing the PVA nanofibers by dipping them into deionized water. ${ }^{31}$ Then, a thin PEDOT:PSS film was spin-coated on the Ag NNs to protect them from environmental corrosion. The cross-sectional view of the hybrid EC electrode is schematically illustrated in Fig. 1B.

\section{Deposition of the EC hybrid film}

The EC hybrid film was fabricated by magnetron sputtered $\mathrm{WO}_{3}$ coated on the surface of the $\mathrm{WO}_{3} / \mathrm{Ag}$ NN/PEDOT:PSS hybrid electrode for 10-600 $\mathrm{nm}$ by only modulating the sputtering time. The control group was prepared by sputtering $\mathrm{WO}_{3}$ on an original PET/Ag NN substrate with the same parameters.

Four kinds of EC device were fabricated for investigating chemical stability, $\mathrm{Ag} \mathrm{NN} / \mathrm{WO}_{3}, \mathrm{WO}_{3} / \mathrm{Ag} \mathrm{NN} / \mathrm{WO}_{3}, \mathrm{Ag} \mathrm{NN} /$ PEDOT:PSS $/ \mathrm{WO}_{3}$ and $\mathrm{WO}_{3} / \mathrm{Ag}$ NN/PEDOT:PSS $\mathrm{WO}_{3}$, on PET substrates.

The mechanical flexibility of the $\mathrm{WO}_{3} / \mathrm{Ag}$ NN/PEDOT:PSS $\mathrm{WO}_{3}$ hybrid film was investigated on three different substrates (PET, PE cling wrap and PDMS) under bending, twisting and stretching, respectively.

\section{Characterization}

The $R_{\mathrm{S}}$ values of the films were measured using a four-point probe (4 Probes Tech RTS-8). The recorded values for $R_{\mathrm{S}}$ were averaged after 6 measurements. Scanning electron microscopy (SEM, Hitachi SU-70) and EDS mapping were used to observe the morphology of the fixed materials. The luminance (Cd $\mathrm{m}^{-2}$ ) of a green light-emitting diode was simultaneously detected by a Fiber Optic Spectrometer (Ocean Optics syc/syc) at flat and $720^{\circ}$ twisted states. An ultraviolet (UV)-visible (VIS)near-infrared (NIR) spectrophotometer (Perkin Elmer Lambda 750) was utilized to measure the transmittance. All electrochemical measurements were carried out with a threeelectrode configuration. The $\mathrm{WO}_{3} / \mathrm{Ag}$ NN/PEDOT:PSS/WO $\mathrm{WO}_{3}$ hybrid film served as the working electrode, a platinum (Pt) foil as the counter electrode, a saturated calomel electrode (SCE) worked as the reference electrode, and the electrolyte was $1 \mathrm{M}$ lithium perchlorate $\left(\mathrm{LiClO}_{4}\right)$ (98\%, Aladdin)/ propylene carbonate (PC) (99\%, Aladdin) solution. The adhesion test (as previously reported by Yang et al. ${ }^{32}$ ) was carried out using tape (3 M, 9080, $1 \mathrm{~cm}$ width) which was stuck on the surface of the film with finger pressure, and then removed (Fig. S1, ESI $\dagger$ ). Mechanical tests such as bending, twisting and stretching were implemented on the $\mathrm{WO}_{3} / \mathrm{Ag}$ NN/PEDOT:PSS hybrid electrode film, and were all performed using a spiral stand test bench (Handpi HLB).

\section{Results and discussion}

\section{Characteristics of the hybrid EC electrodes}

Fig. 2 displays the morphology and composition of the hybrid electrodes. Before the transferring of the $\mathrm{Ag}$ NNs, ultra-thin $\mathrm{WO}_{3}$ was deposited on the transparent PET substrate, which had nearly no effect on transparency (Fig. 2A). Fig. 2B shows a typical example of the $\mathrm{Ag} \mathrm{NN}$ electrodes where all the nanotroughs are interconnected with each other. The length of the nanotroughs can reach several centimeters (Fig. S2 $\dagger$ ). The diameter of the Ag networks (200-800 nm) can be simply controlled by adjusting the electrospinning parameters. The enlarged scanning electron microscopy (SEM) image in the inset of Fig. 2B shows the hollow cross-junctional structure of the networks, indicating the dissolution of the PVA nanofibers. The hollow concave shape facilitates transmittance by reducing the electromagnetic crosssection. ${ }^{33}$ Compared with the bulk-like structure, this hollow NN exhibits excellent conductivity and optical transparence, which can be explained by percolation effects. ${ }^{34}$ As shown in Fig. 2B-D, the crystalline structure of $\mathrm{WO}_{3}$ cannot be observed and the atomic number ratio of elemental $\mathrm{W}$ and $\mathrm{O}$ substantially conforms to the ratio of $1: 3$ in $\mathrm{WO}_{3}$, according to EDX analysis (Fig. S3†). The "X" shaped cross-junctions of the Ag NNs provide uniform interconnections, which lead to the benefits of outstanding mechanical flexibility and stretchability. ${ }^{35}$ Fig. $2 \mathrm{E}$ presents the corresponding energy dispersive spectroscopy (EDS) element mappings of the hybrid film, where uniform sulfur (S) element is stacked on the top and exists in the gaps of Ag NNs, indicating that PEDOT:PSS can only bind to Ag NNs on the substrate. Moreover, compared with single layer Ag NNs, the additional $\mathrm{WO}_{3}$-bottom layer can significantly improve the adhesion between $\mathrm{Ag}$ NNs and the substrate, which is verified using the Scotch tape adhesion test (Fig. S1 $\dagger$ ).

The density of Ag NNs is critical to the optical transparency and electrical conductivity of the hybrid film. ${ }^{36}$ It is easy to
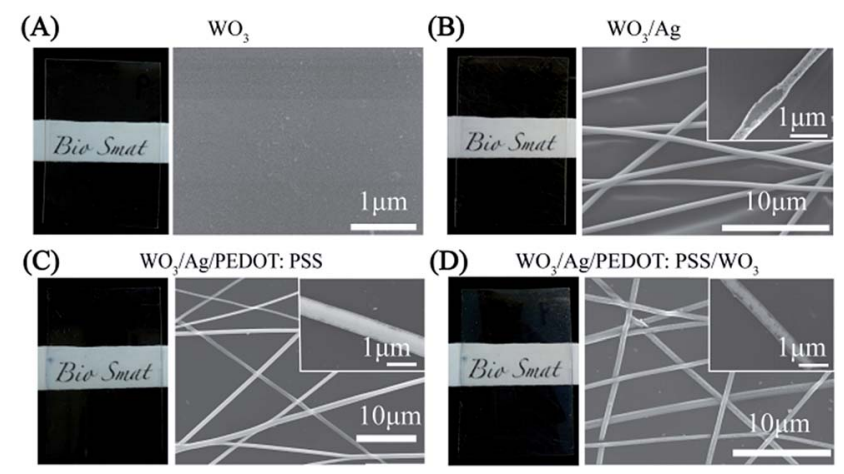

(D) $\quad \mathrm{WO}_{3} / \mathrm{Ag} / \mathrm{PEDOT}: \mathrm{PSS} / \mathrm{WO}_{3}$

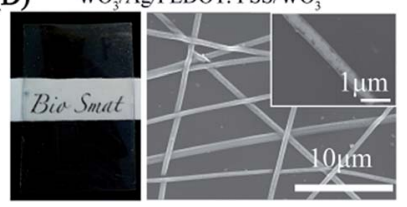

(E)
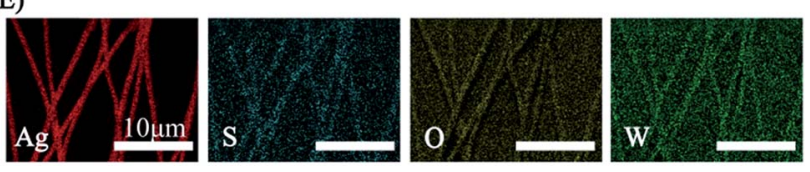

Fig. 2 Photographs (left) and corresponding SEM images (right) of the (A) $\mathrm{WO}_{3}$, (B) $\mathrm{WO}_{3} / \mathrm{Ag} \mathrm{NN}$, (C) $\mathrm{WO}_{3} / \mathrm{Ag} \mathrm{NN} / \mathrm{PEDOT}$ :PSS and (D) $\mathrm{WO}_{3} / \mathrm{Ag}$ NN/PEDOT:PSS $/ \mathrm{WO}_{3}$ films. (E) Corresponding EDS element mappings of the $\mathrm{WO}_{3} / \mathrm{Ag} \mathrm{NN/PEDOT:PSS/WO}$ hybrid film. 
modify the density of $\mathrm{Ag}$ NNs by altering the electrospinning parameters and the number of Ag NN layers transferred. Dense $\mathrm{Ag}$ NNs provide a uniform, interconnected network which achieves high conductivity with a low $R_{\mathrm{s}}$, but is harmful to the transparency. Fig. 3A shows the relationship between the optical transmittance of the $\mathrm{Ag} \mathrm{NN}$ films and their $R_{\mathrm{s}}$ values at a wavelength of $550 \mathrm{~nm}$. Obviously, the transmittance is proportional to the $R_{\mathrm{s}}$ of the $\mathrm{Ag} \mathrm{NN}$ films below $2.50 \Omega \mathrm{sq}^{-1}$, and then the curve's growth begins to slow and stabilize. Fig. 3B shows that the transmittance of the hybrid film also increases with enhancing $R_{\mathrm{S}}$ values in the visible range. An $R_{\mathrm{S}}$ of $1.08 \Omega$ $\mathrm{sq}^{-1}$ was achieved at over $85 \%$ transparency, and the excellent optical and electrical performance exceeds commonly used ITO, which was verified by the corresponding comparisons of transmittance and $R_{\mathrm{S}}$ values among commercial ITO, the $\mathrm{Ag}$ NNs and the $\mathrm{WO}_{3} / \mathrm{Ag} \mathrm{NN}, \mathrm{Ag} \mathrm{NN} / \mathrm{PEDOT}$ :PSS and $\mathrm{WO}_{3} / \mathrm{Ag} \mathrm{NN} /$ PEDOT:PSS hybrid films (Fig. S4†). To investigate the mechanical flexibility of the hybrid electrode, each sample with a size of $2.5 \mathrm{~cm} \times 1 \mathrm{~cm}$ was bent to a radius of $0.5 \mathrm{~cm}$ and then released to its initial position 5000 times. It is apparent from Fig. $3 \mathrm{C}$ that smaller changes in resistance are observed for $\mathrm{Ag}$ NNs and
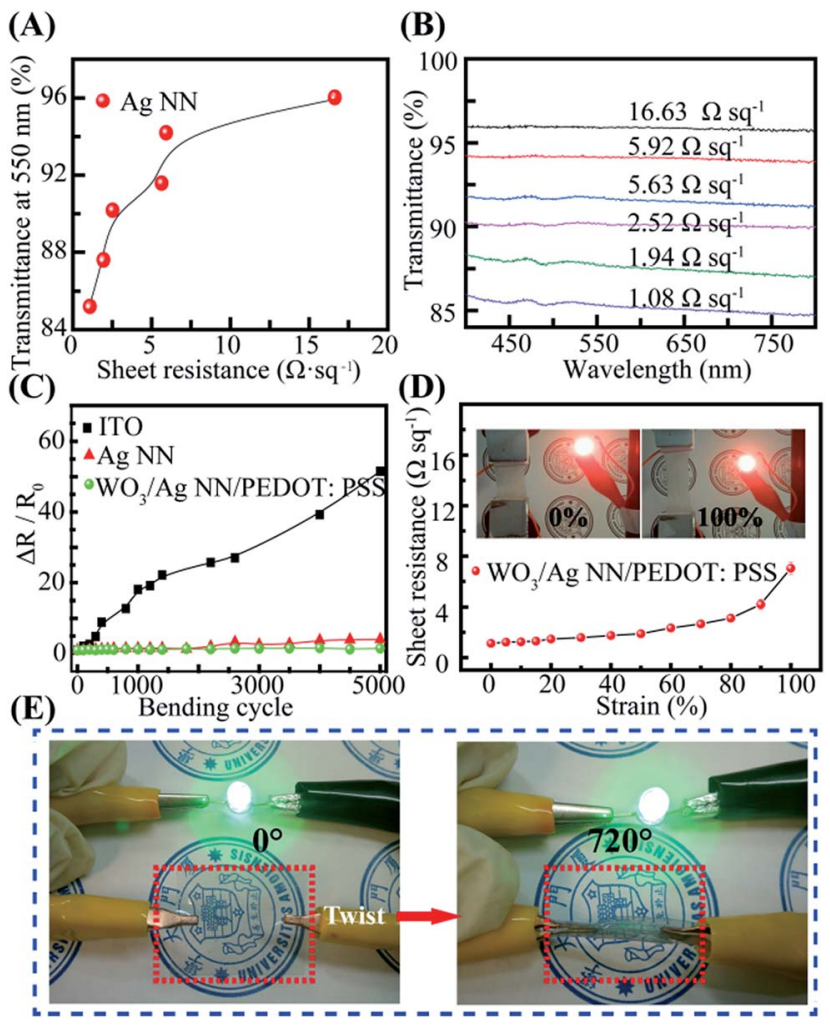

Fig. 3 Mechanical stability of the hybrid electrode. (A) The relationship between transmittance at $550 \mathrm{~nm}$ and the sheet resistance of the $\mathrm{Ag}$ $\mathrm{NNs}$, (B) the visible transmittance spectra of the Ag NNs vs. different $R_{\mathrm{s}}$ values. (C) The mechanical flexibility test of ITO, the Ag NNs and the $\mathrm{WO}_{3} / \mathrm{Ag}$ NN/PEDOT:PSS hybrid film on a PET substrate after 5000 bending cycles at a radius of $0.5 \mathrm{~cm}$. (D) The $R_{\mathrm{s}}$ values of the $\mathrm{WO}_{3} / \mathrm{Ag}$ NN/PEDOT:PSS film on Ecoflex as a function of tensile strain. (E) Photographs of the $\mathrm{WO}_{3} / \mathrm{Ag} / \mathrm{PEDOT}$ :PSS/ $\mathrm{WO}_{3}$ hybrid film connected in series with a green light-emitting diode when flattened (left) and forcible twisting (right). hybrid electrodes with $405 \%$ and $154 \%$ increases, respectively, while ITO suffers from serious damage and its $R_{\mathrm{S}}$ increases sharply until $5152 \%$ after bending 5000 times. In Fig. 3C, $\Delta R / R_{0}$ represents the $R_{\mathrm{S}}$ variations obtained during repeated bending, $R_{0}$ is the initial $R_{\mathrm{s}}, \Delta R$ is the difference in the measured $R_{\mathrm{S}}$ after the bending cycles minus $R_{0}$. It is worth noting that there was only a $54 \%$ increase in $\Delta R / R_{0}$ for the hybrid film, and a $305 \%$ increase for the $\mathrm{Ag} \mathrm{NN}$ film, indicating that the additional $\mathrm{WO}_{3}$ bottom and PEDOT:PSS can improve the mechanical flexibility of $\mathrm{Ag}$ NNs.

Fig. 3D shows the $R_{\mathrm{S}}$ of the hybrid film on an Ecoflex substrate as a function of tensile strain and the insets are photographs of the hybrid electrode on Ecoflex film with different tensile strains. Obviously, $R_{\mathrm{S}}$ increased slowly when the tensile strain increased from $0 \%$ to $80 \%$, and adverse effects with cracking of the Ag NNs (Fig. S5 $\dagger$ ) would follow at above $80 \%$ with a sudden change in the curve. The corresponding video of the tensile strain test is provided in the ESI as Video $\mathrm{S} 1, \uparrow$ indicating that the film maintained good electrical conductivity until the tensile strain was larger than $150 \%$. The adhesion property is another critical factor correlated with the stability and durability of the integrated devices. For the hybrid film, the $\mathrm{Ag} \mathrm{NN}$ layer was coated by ultra-thin $\mathrm{WO}_{3}$-bottom and PEDOT:PSS layers, which could act as protective layers. The Ag NN film without protective layers was readily torn from the PET substrate by scotch tape, whereas the hybrid film maintained integrity. It is notable that the hybrid film maintains good mechanical conductivity, confirmed by connecting it in series with a green light-emitting diode (LED) and lighting up the LED during $720^{\circ}$ forcible twisting (Fig. 3E). The 96.6\% luminance $\left(\mathrm{Cd} \mathrm{\textrm {m } ^ { - 2 }}\right.$ ) retention demonstrated the mechanical robustness and stability of the hybrid film.

\section{Chemical stability of the hybrid EC film}

Cyclic voltammetry (CV) measurements of the hybrid film with a $\mathrm{WO}_{3}$ EC layer were carried out using a three-electrode configuration, as shown in Fig. 4(A and B). The $\mathrm{WO}_{3} / \mathrm{Ag} \mathrm{NN} /$ PEDOT:PSS $/ \mathrm{WO}_{3}$ hybrid film, Pt foil and saturated calomel electrode (SCE) served as the working electrode, counter electrode and reference electrode, respectively. The representative peak for $\mathrm{WO}_{3}$ was observed at different potential scan rates from 30 to $100 \mathrm{mV} \mathrm{s}^{-1}$ in the $\mathrm{CV}$ curves, which could be attributed to the intercalation (or deintercalation) of $\mathrm{Li}^{+}$and $\mathrm{e}^{-}$ into (or out of) $\mathrm{WO}_{3}$, described as:

$$
x \mathrm{Li}^{+}+x \mathrm{e}^{-}+\mathrm{WO}_{3} \leftrightarrow \mathrm{Li}_{X} \mathrm{WO}_{3}
$$

The insertion of $\mathrm{Li}^{+}$and $\mathrm{e}^{-}$results in a reduction of the $\mathrm{W}^{6+}$ to a lower valence as a $\mathrm{W}^{6-x}$ state, leading to the color change of the $\mathrm{WO}_{3}$ EC film to a dark blue color during an applied negative bias potential. On the contrary, the film's color will fade when a positive bias potential is applied, with the reduced $\mathrm{W}^{6-x}$ ions oxidized back due to the extraction of $\mathrm{Li}^{+}$and $\mathrm{e}^{-}$from the $\mathrm{WO}_{3}$ film. It is a reversible change due to the chemical reaction between oxidized (bleached or transparent) and reduced (colored or dark blue) states. As shown in Fig. 4A, the shifting 
(A)

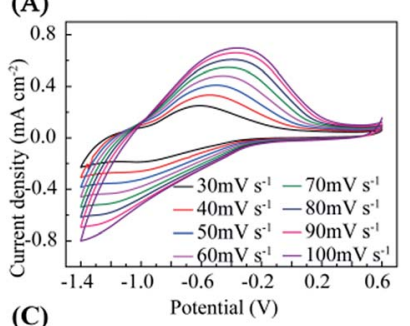

(C)
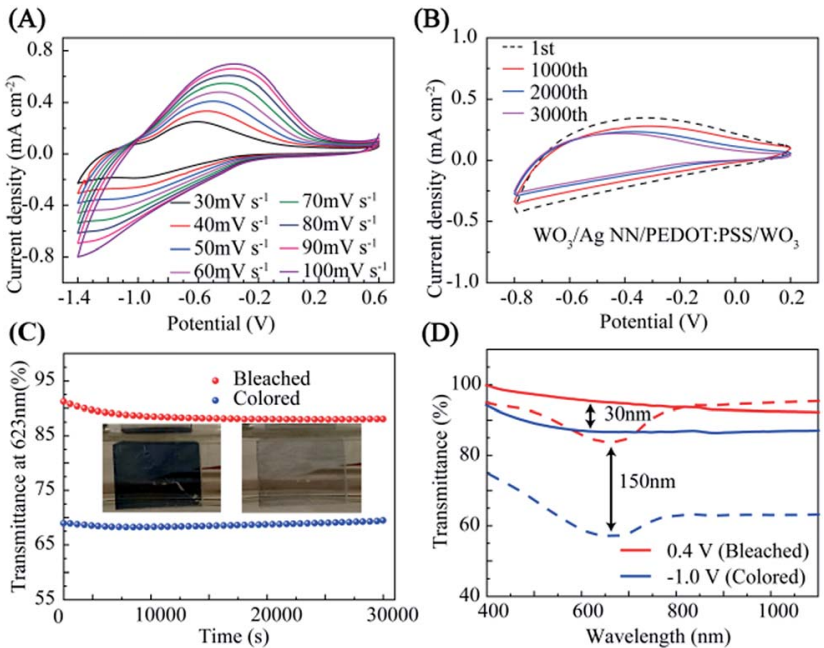

(D)

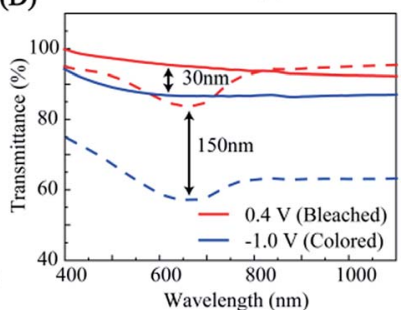

Fig. 4 Electrochemical performance of the EC hybrid film. Cyclic voltammograms of the hybrid EC film (A) at different potential scan rates from 30 to $100 \mathrm{mV} \mathrm{s}^{-1}$ and (B) at a scanning rate of $80 \mathrm{mV} \mathrm{s}^{-1}$ in the potential range of -0.8 (colored) to $0.2 \mathrm{~V}$ (bleached). (C) Cyclic performance of the hybrid EC film. (D) Transmittance spectra of $30 \mathrm{~nm}$ (solid line) and $150 \mathrm{~nm}$ (dashed line) at bleached state $(0.4 \mathrm{~V})$ and colored state $(-1.0 \mathrm{~V})$

and deforming of the oxidation and reduction peaks with increasing voltage scan rate is possibly due to ion migration and electron trapping/de-trapping at the interface of the hybrid film in the redox process. ${ }^{37,38}$

Fig. 4B indicates that the hybrid film has good reversibility, stability and durability in the insertion and extraction of $\mathrm{Li}^{+}$, and the $\mathrm{CV}$ curves are displayed at the $1000^{\text {th }}, 2000^{\text {th }}$ and $3000^{\text {th }}$ cycle at room temperature, measured in $1 \mathrm{M} \mathrm{LiClO}_{4} / \mathrm{PC}$ electrolyte. There was a slight decrease during the first 1000 cycles, and then the current density remained stable during $1000-3000$ cycles. The EC evaluation of the hybrid film was conducted in a three-electrode configuration by means of an electrochemical workstation with a UV-VIS-NIR spectrometer, as shown in Fig. S6. $\dagger$ The hybrid film presented a noticeable EC phenomenon with an optical modulation of $23 \%$ contrast between coloring and bleaching at $623 \mathrm{~nm}$, under a narrow potential range between -1.0 and $0.4 \mathrm{~V}$, when the thickness of the external $\mathrm{WO}_{3}$ was $150 \mathrm{~nm}$. The $\mathrm{WO}_{3}$ on the hybrid electrode sustains $86 \%$ of the initial optical contrast after cycling for 30000 s, as shown in Fig. 4C. Digital photographs of $\mathrm{WO}_{3}$ on the hybrid electrode in its bleached state and colored state are shown in the insets of Fig. 4C.

The transmittance modulations of the EC film could be controlled by adjusting the thickness of the external $\mathrm{WO}_{3}$ film. As shown in Fig. 4D, at wavelengths from 300 to $1100 \mathrm{~nm}$, although the sample with $150 \mathrm{~nm} \mathrm{WO}_{3}$ exhibits a lower transmittance at the bleached and colored states compared with the $30 \mathrm{~nm}$ sample, the optical contrast is twice over that of the $30 \mathrm{~nm}$ sample. The transmittance modulations of the devices are directly proportional to the thickness of the $\mathrm{WO}_{3}$ films until a maximum value is reached $(\sim 50 \%)$ when the thickness are higher than $\sim 250 \mathrm{~nm}$, as shown in Fig. S7.†
To investigate the chemical stability of different EC films, transmittances, corresponding with the colored and bleached states of the different films, are displayed in Fig. 5A. It should be noted that without the $\mathrm{WO}_{3}$-bottom layer, the optical contrasts of $\mathrm{Ag} \mathrm{NN} / \mathrm{WO}_{3}$ and $\mathrm{Ag} \mathrm{NN} / \mathrm{PEDOT}: \mathrm{PSS} / \mathrm{WO}_{3}$ were only $0.2 \%$ and $11 \%$ at the $40^{\text {th }}$ cycle, while those of $\mathrm{WO}_{3} / \mathrm{Ag} \mathrm{NN} / \mathrm{WO}_{3}$ and $\mathrm{WO}_{3} /$ Ag NN/PEDOT:PSS $/ \mathrm{WO}_{3}$ were $7 \%$ and $23 \%$, respectively. Moreover, the $T_{\text {average }}$ values of bleached state $\mathrm{WO}_{3} / \mathrm{Ag} \mathrm{NN} / \mathrm{WO}_{3}$ and $\mathrm{WO}_{3} / \mathrm{Ag} \mathrm{NN} / \mathrm{PEDOT}: \mathrm{PSS} / \mathrm{WO}_{3}$ are above $70 \%$ and $90 \%$, more than the $65 \%$ and $70 \%$ obtained for $\mathrm{Ag} \mathrm{NN} / \mathrm{WO}_{3}$ or $\mathrm{Ag} \mathrm{NN} /$ PEDOT:PSS $/ \mathrm{WO}_{3}$, demonstrating that the presence of the $\mathrm{WO}_{3}$ bottom is beneficial for achieving higher transmittance and better cycling stability and for preventing direct contact between $\mathrm{Ag}$ NNs and the substrate. Compared with the $\mathrm{WO}_{3} / \mathrm{Ag}$ $\mathrm{NN} / \mathrm{WO}_{3}$ film, the $\mathrm{WO}_{3} / \mathrm{Ag} \mathrm{NN} / \mathrm{PEDOT}: \mathrm{PSS} / \mathrm{WO}_{3}$ film sustains a larger optical modulation and subtler degradation, which can be attributed to the PEDOT:PSS layer protecting the Ag NNs from directly contacting the external environment and enhancing adhesion on the substrate.

Apart from optical contrast and cycling life, obtaining switching times between colored states and bleached states under commutative potential is also critical for evaluating the kinetic performance of the ECDs. ${ }^{39}$ The switching time is defined as the time required for the integrated device to reach $90 \%$ of the transmittance change between the steady bleached and colored states. ${ }^{31}$ For the $\mathrm{WO}_{3} / \mathrm{Ag}$ NN/PEDOT:PSS $/ \mathrm{WO}_{3}$ hybrid film, the switching times, as shown in Fig. 5B, are 0.75 and $1.82 \mathrm{~s}$ for bleaching and coloration, respectively, which is faster than Lee's group ( 4 and $1 \mathrm{~s}$, respectively) ${ }^{6}$ and Cai et al. (2.8 and $1.9 \mathrm{~s}$, respectively), ${ }^{3}$ with EC films based on a $\mathrm{Ag} \mathrm{NW}$ conductor and an electrodeposited $\mathrm{WO}_{3} \mathrm{EC}$ layer.

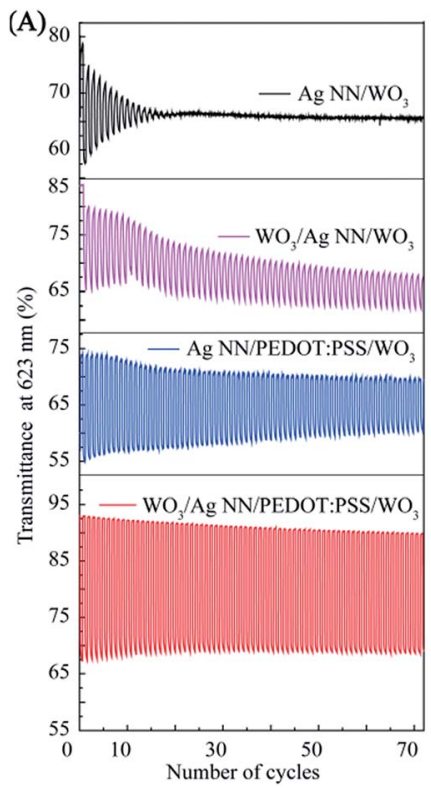

(B)

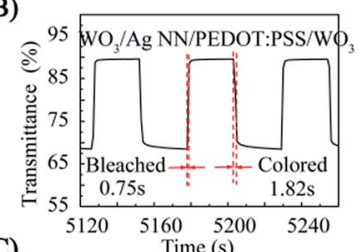

(C)

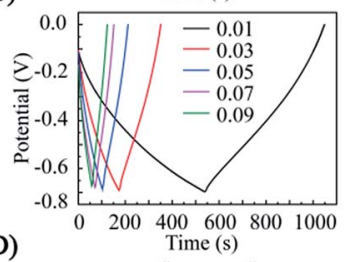

(D)

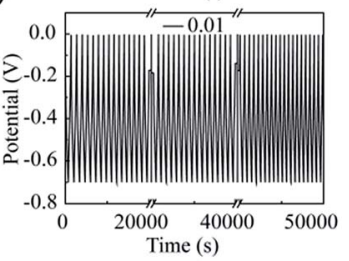

Fig. 5 (A) Characterization of the coloring and bleaching rate by measuring the switching time. Statistical results indicate a bleaching time of 0.75 seconds and coloring time of 1.82 seconds. Galvanostatic charge/discharge profile at (C) current densities from 0.01 to $0.1 \mathrm{~mA}$ $\mathrm{cm}^{-2}$, and (D) $0.01 \mathrm{~mA} \mathrm{~cm}^{-2}$. 
As we know, the intercalation (or deintercalation) of ions and electrons into (or out of) $\mathrm{WO}_{3}$ during the coloration (or bleaching) process can correspond exactly to the charging (or discharging) process of supercapacitive behavior, as described in eqn (1). ${ }^{3,40}$ That is to say, the reversible color variation of an ECD can simultaneously monitor its level of stored energy. ${ }^{\mathbf{4 1 4 2}}$ The functional ECD must be adequately fast for observation with highly transparent conductive, stable and durable electrodes as the current collector, especially at high current charging/discharging processes. To this end, an electrochromicsupercapacitor (EC-SC) can be designed to simultaneously realize transmittance adjustment and energy storage. ${ }^{43,44}$ Fig. 5C and $\mathrm{D}$ display the charge/discharge curves at different current densities and the corresponding long-term stability test of the EC-SC. The downward lines correspond with the charging and the upward lines with the discharging processes. Charging is related to the intercalation of $\mathrm{Li}^{+}$and $\mathrm{e}^{-}$into the $\mathrm{WO}_{3}$ film, with a subsequently observed change to dark blue color attributed to the reduction of $\mathrm{W}^{6+}$ ions to $\mathrm{W}^{6-x}$ ions, and the discharging process corresponds to the oxidation of the $\mathrm{W}^{6-x}$ ions with color bleaching. The specific capacitance $\left(C, \mathrm{mF} \mathrm{cm}^{-2}\right)$ can be calculated as follows: ${ }^{45}$

$$
C=\frac{J \Delta t}{\Delta V}
$$

where $J\left(\mathrm{~mA} \mathrm{~cm}^{-2}\right)$ denotes the discharging current density and $\Delta t(\mathrm{~s})$ and $\Delta V(\mathrm{~V})$ represent the total discharging time and the potential drop during discharging, respectively. The hybrid film exhibits a specific capacitance of 7.23, 7.74, 7.96, 8.19 and 8.76 $\mathrm{mF} \mathrm{cm}{ }^{-2}$ at $0.01,0.03,0.05,0.07$ and $0.09 \mathrm{~mA} \mathrm{~cm}^{-2}$ (Fig. 5C), respectively. Furthermore, the hybrid film maintains a capacitance retention of $73.2 \%$ at $0.01 \mathrm{~mA} \mathrm{~cm}^{3}$ after cycling testing for $50000 \mathrm{~s}$, indicating the stability of the capacitor's performance under prolonged charging/discharging processes, as shown in Fig. 5D.

\section{Mechanical robustness of the hybrid EC film}

Cling wrap is a common thin plastic film typically used for sealing items in containers to keep them fresh over a longer period of time, which is ultra-thin, highly flexible, sold in rolls in boxes with a low price and is easy to access. Constructing EC films on cling wrap is more suitable for developing highly flexible and ultra-thin ECDs which can be stuck on the glass of cars or buildings for reducing energy consumption, or for developing color-changing e-skin (as shown at the top of Fig. 6B), rather than replacement with exorbitant EC smart windows. Here, we successfully fabricate the hybrid EC film on cheap household PE cling wrap, as shown in Fig. 6(A and B). Fig. 6C illustrates that the ultra-thin EC film on PE cling wrap substrate maintains stable and reversible color changes between bleached and colored states after strong repeated kneading (Video S2, ESI $\dagger$ ), indicating excellent mechanical robustness. A real-time switching test from the "ON" (bleached) to the "OFF" (colored) state of the "XMU" patterned EC hybrid film during bending at a repeatedly applied voltage between $V_{\mathrm{ON}}$ $(0.4 \mathrm{~V})$ and $V_{\text {OFF }}(-1 \mathrm{~V})$ was carried out, and the period was $5 \mathrm{~s}$. This was to verify that the EC film exhibits good electrochemical
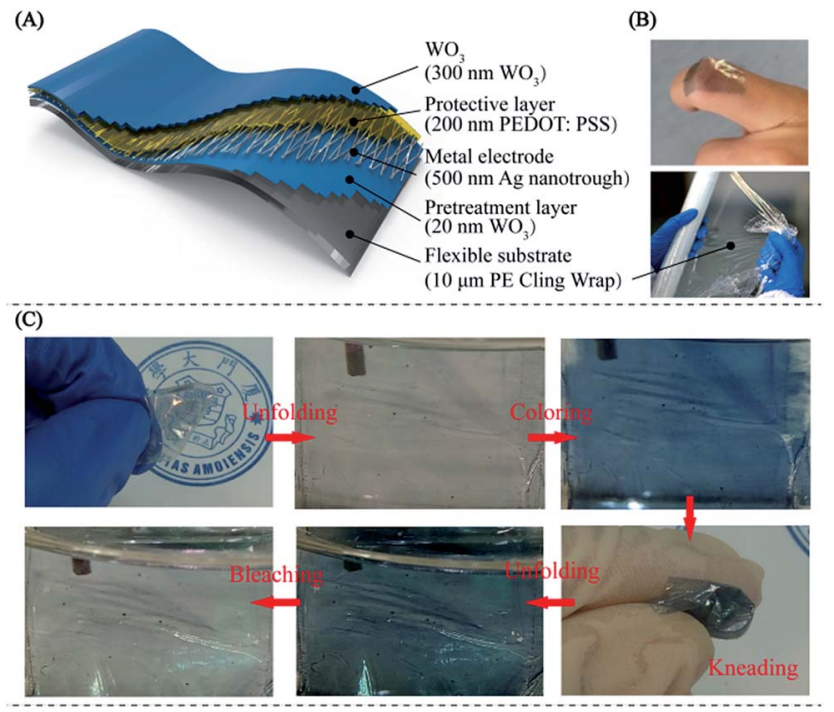

(D)

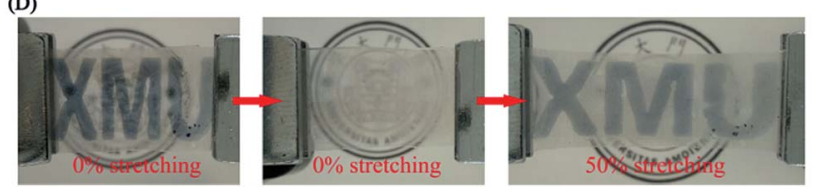

Fig. 6 Mechanical robustness of the hybrid EC films on PE cling wrap and PDMS film. (A) Schematic illustration of the structure of the PE cling wrap-based hybrid EC film. (B) The color-changing e-skin (EC film) on one finger (top), and PE cling wrap (bottom). (C) Upon folding and strong kneading, the PE-based hybrid EC film still displays the ability of coloring and bleaching, indicating excellent mechanical flexibility. (D) With $50 \%$ tensile strain stretching, the hybrid EC film on a PDMS substrate could also sustain its mechanical stability and electrochromic properties.

stability during bending and is demonstrated in the ESI (Video S3 and Fig. S8). $\dagger$

The tensile strain tests for the "XMU" patterned hybrid EC film on a flexible PDMS substrate are shown in Fig. 6D. In the first step, the device was in the colored state without any strain and then the logo "XMU" disappeared (bleached) after the application of a positive voltage $(0.4 \mathrm{~V})$. Then, $50 \%$ tensile strain was applied on the patterned EC film using a spiral stand test bench, inverse voltage was applied and the logo appeared again. The corresponding SEM images, as shown in Fig. S5, $\dagger$ indicate that the Ag NNs in the patterned hybrid EC film remain intact while the continuous $\mathrm{WO}_{3}$ layer is fractured during stretching, demonstrating the unique hollow cross-junctional structure of the TCE, which can bear stretching and bending to support the working of the ECD. The $\mathrm{WO}_{3} / \mathrm{Ag}$ NN/PEDOT:PSS EC hybrid film, which was successfully constructed on the different PET, cling wrap and PDMS flexible substrates with resounding mechanical flexibility, stability and EC performance, could be a strikingly attractive candidate for flexible and wearable electronic applications.

\section{Conclusions}

In conclusion, a flexible sandwiched $\mathrm{WO}_{3} / \mathrm{Ag}$ NN/PEDOT:PSS electrode was successfully fabricated which simultaneously 
displays prominent conductivity (sheet resistance as low as 1.08 $\Omega \mathrm{sq}^{-1}$ ) and transparency (85\%). It was further revealed that this electrode can adhere tightly to $\mathrm{WO}_{3}$, together forming a flexible electrochromic device. This ECD is not only extremely flexible upon mechanical bending, twisting, stretching and even strong kneading, but also preserves excellent cycling stability. In addition, this ECD also possesses advantages such as rapid switching time ( $0.75 \mathrm{~s}$ for bleaching and $1.82 \mathrm{~s}$ for coloring) and $86 \%$ retention of optical contrast even after 30000 s cycling. On the other hand, we also confirmed that our electrode can be fabricated on various flexible substrates such as PE, PDMS and Ecoflex. Our work provides new opportunities for the next generation of flexible and wearable electronic applications on various flexible substrates such as PE, PDMS and Ecoflex. Furthermore, a considerable application prospect in energy storage, such as in a supercapacitor with an extraordinary charging/discharging stability that can sense changes using color mutation, is demonstrated.

\section{Conflicts of interest}

There are no conflicts to declare.

\section{Acknowledgements}

This work was supported by the National Natural Science Foundation of China (No. 51502253, U1405226), the Guangdong Natural Science Foundation (2016A030310369), the Fujian Natural Science Foundation (No. 2017J01104), the Fundamental Research Funds for the Central Universities of China (No. 20720180013), the "111" Project (B16029), the Doctoral Fund of the Ministry of Education (20130121110018) and the 1000 Talents Program funding from the Xiamen university.

\section{References}

1 X. Pu, M. M. Liu, X. Y. Chen, J. M. Sun, C. H. Du, Y. Zhang, J. Y. Zhai, W. G. Hu and Z. L. Wang, Sci. Adv., 2017, 3, e1700015.

2 B. Han, K. Pei, Y. L. Huang, X. J. Zhang, Q. K. Rong, Q. G. Lin, Y. F. Guo, T. Y. Sun, C. F. Guo, D. Carnahan, M. Giersig, Y. Wang, J. W. Gao, Z. F. Ren and K. Kempa, Adv. Mater., 2014, 26, 873-877.

3 G. F. Cai, P. Darmawan, M. Q. Cui, J. X. Wang, J. W. Chen, S. Magdassi and P. S. Lee, Adv. Energy Mater., 2016, 6, 1501882.

4 S. Park, K. Parida and P. S. Lee, Adv. Energy Mater., 2017, 7, 1701369.

5 R. Baetens, B. P. Jelle and A. Gustavsen, Sol. Energy Mater. Sol. Cells, 2010, 94, 87-105.

6 C. Y. Yan, W. B. Kang, J. X. Wang, M. Q. Cui, X. Wang, C. Y. Foo, K. J. Chee and P. S. Lee, ACS Nano, 2014, 8, 316322.

7 C. Lee, Y. Oh, I. S. Yoon, S. H. Kim, B. K. Ju and J. M. Hong, Sci. Rep., 2018, 8, 2763.

8 J. Jensen and F. C. Krebs, Adv. Mater., 2014, 26, 7231-7234.
9 K. R. Li, Q. H. Zhang, H. Z. Wang and Y. G. Li, J. Mater. Chem. C, 2016, 4, 5849-5857.

10 W. Liu, M. S. Song, B. Kong and Y. Cui, Adv. Mater., 2017, 29, 1603436.

11 G. D. Zhou, Y. Q. Yao, Z. S. Lu, X. D. Yang, J. J. Han, G. Wang, X. Rao, P. Li, Q. Liu and Q. L. Song, Nanotechnology, 2017, 28, 425202.

12 G. D. Zhou, Y. Q. Yao, X. S. Zhao, X. Q. Liu, B. Sun and A. K. Zhou, RSC Adv., 2016, 6, 59370-59374.

13 A. Pierre, I. Deckman, P. B. Lechene and A. C. Arias, Adv. Mater., 2015, 27, 6411-6417.

14 P. M. Beaujuge and J. R. Reynolds, Chem. Rev., 2010, 110, 268-320.

15 P. C. Hsu, S. Wang, H. Wu, V. K. Narasimhan, D. S. Kong, H. R. Lee and Y. Cui, Nat. Commun., 2013, 4, 2522.

16 T. F. Qiu, B. Luo, M. H. Liang, J. Ning, B. Wang, X. L. Li and L. J. Zhi, Carbon, 2015, 81, 232-238.

17 G. D. Zhou, L. H. Xiao, S. J. Zhang, B. Wu, X. Q. Liu and A. K. Zhou, J. Alloys Compd., 2017, 722, 753-759.

18 G. D. Zhou, S. K. Duan, P. Li, B. Sun, B. Wu, Y. Q. Yao, X. D. Yang, J. J. Han, J. G. Wu and G. Wang, Adv. Electron. Mater., 2018, 1700567.

19 J. Z. Chen, W. Y. Ko, Y. C. Yen, P. H. Chen and K. J. Lin, ACS Nano, 2012, 6, 6633-6639.

20 L. Liang, J. J. Zhang, Y. Y. Zhou, J. F. Xie, X. D. Zhang, M. L. Guan, B. C. Pan and Y. Xie, Sci. Rep., 2013, 3, 1936.

21 G. D. Zhou, W. X. Zhao, X. Q. Ma and A. K. Zhou, J. Alloys Compd., 2016, 679, 47-53.

22 W. X. Guo, Z. J. Xu, F. Y. Zhang, S. Y. Xie, H. Y. Xu and X. Y. Liu, Adv. Funct. Mater., 2016, 26, 8855-8884.

23 S. S. Yao and Y. Zhu, Adv. Mater., 2015, 27, 1480-1511.

24 W. F. Zhang, B. F. Zhao, Z. C. He, X. M. Zhao, H. T. Wang, S. F. Yang, H. B. Wu and Y. Cao, Energy Environ. Sci., 2013, 6, 1956-1964.

25 M. Aleksandrova, V. Videkov, R. Ivanova, A. K. Singh and G. S. Thool, Mater. Lett., 2016, 174, 204-208.

26 Y. C. Tseng, A. U. Mane, J. W. Elam and S. B. Darling, Sol. Energy Mater. Sol. Cells, 2012, 99, 235-239.

27 Y. J. Noh, S. S. Kim, T. W. Kim and S. I. Na, Sol. Energy Mater. Sol. Cells, 2014, 120, 226-230.

28 Y. S. Kim, M. H. Chang, E. J. Lee, D. W. Ihm and J. Y. Kim, Synth. Met., 2014, 195, 69-74.

29 X. D. Wang, Y. F. Zhang, X. J. Zhang, Z. H. Huo, X. Y. Li, M. L. Que, Z. C. Peng, H. Wang and C. F. Pan, Adv. Mater., 2018, 30, 1706738.

30 W. B. Kang, M. F. Lin, J. W. Chen and P. S. Lee, Small, 2016, 12, 6370-6377.

31 P. J. Yao, S. Y. Xie, M. D. Ye, R. Yu, Q. Liu, D. D. Yan, W. W. Cai, W. X. Guo and X. Y. Liu, RSC Adv., 2017, 7, 29088-29095.

32 R. Zhu, C. H. Chung, K. C. Cha, W. B. Yang, Y. B. Zheng, H. P. Zhou, T. B. Song, C. C. Chen, P. S. Weiss, G. Li and Y. Yang, ACS Nano, 2011, 5, 9877-9882.

33 H. Wu, D. S. Kong, Z. C. Ruan, P. C. Hsu, S. Wang, Z. F. Yu, T. J. Carney, L. B. Hu, S. H. Fan and Y. Cui, Nat. Nanotechnol., 2013, 8, 421-425.

34 S. De and J. N. Coleman, MRS Bull., 2011, 36, 774-781. 
35 B. W. An, E. J. Gwak, K. Kim, Y. C. Kim, J. Jang, J. Y. Kim and J. U. Park, Nano Lett., 2016, 16, 471-478.

36 T. C. Wang, L. J. Chang, S. Kong, S. Yang, Y. Jia and C. P. Wong, Monatsh. Chem., 2014, 145, 61-64.

37 G. D. Zhou, B. Sun, Y. Q. Yao, H. H. Zhang, A. K. Zhou, K. Alameh, B. F. Ding and Q. L. Song, Appl. Phys. Lett., 2016, 109, 143904.

38 G. D. Zhou, Z. S. Lu, Y. Q. Yao, G. Wang, X. D. Yang, A. K. Zhou, P. Li, B. F. Ding and Q. L. Song, J. Appl. Phys., 2017, 121, 155302.

39 A. Kim, Y. Won, K. Woo, C.-H. Kim and J. Moon, ACS Nano, 2013, 7, 1081-1091.

40 M. S. Zhu, W. J. Meng, Y. Huang, Y. Huang and C. Y. Zhi, ACS Appl. Mater. Interfaces, 2014, 6, 18901-18910.
41 Z. J. Bi, X. M. Li, Y. B. Chen, X. K. Xu, S. D. Zhang and Q. X. Zhu, Electrochim. Acta, 2017, 227, 61-68.

42 X. H. Lu, T. Zhai, X. H. Zhang, Y. Q. Shen, L. Y. Yuan, B. Hu, L. Gong, J. Chen, Y. H. Gao, J. Zhou, Y. X. Tong and Z. L. Wang, Adv. Mater., 2012, 24, 938-944.

43 Y. Huang, M. S. Zhu, Y. Huang, Z. X. Pei, H. F. Li, Z. F. Wang, Q. Xue and C. Y. Zhi, Adv. Mater., 2016, 28, 8344-8364.

44 Y. Huang, Y. Huang, W. J. Meng, M. S. Zhu, H. T. Xue, C. S. Lee and C. Y. Zhi, ACS Appl. Mater. Interfaces, 2015, 7, 2569-2574.

45 T. G. Yun, D. Kim, Y. H. Kim, M. Park, S. Hyun and S. M. Han, Adv. Mater., 2017, 29, 1606728. 